\title{
Evaluation of Fixation of Mastectomy Flaps in Reduction of Seroma Formation in Breast Cancer Patients
}

\author{
Ahmed M., Nabil E.S., Samy R., Samy G. \\ Department of General surgery, Ain Shams University \\ Corresponded author: Ahmed M. Omar, Tel: 01223401697, Email: viamatter@gmail.com
}

\begin{abstract}
Background: Seroma is the most common complication following modified radical mastectomy (MRM), as post mastectomy dead space left between skin and anterior chest wall where seroma is formed causing multiple health issues.

Aim of the Work: Is to evaluate the feasibility and efficacy of fixation of skin flaps to anterior chest wall for closing postoperative space with drainage as an alternative to the classic form of mastectomy closure with closed suction drain for MRM for female patients with breast cancer.

Patients and Methods: A total of 60 patients, admitted to the following hospitals: Sydnawy Insurance Hospital, and Ain Shames University Hospitals with a diagnosis of breast cancer and were treated by modified radical mastectomy. Patients were divided into 2 groups group A $(n=30)$ were flap fixing group and group B $(n=30)$ were non flap fixing group all patient were presented with breast cancer with age range of 32 to 75 , postoperative patients were followed and their data were collected and compared.
\end{abstract}

Results: All 60 patients were evaluated as we had no patients who were lost in follow up. Patients' demographics were not different in the two groups. We reported less overall complication in group A than group B, also reduced total seroma volume in group A and reduced number of drain days in group A than B.

Conclusions: Fixation of skin flaps to chest wall and closure of dead space post modified radical mastectomy actually reduce incidence of seroma formation

Keywords: Modified Radical mastectomy, Seroma, Reducing seroma, Fixation of skin flaps

\section{INTRODUCTION}

Breast cancer is a major global problem with nearly one million cases occurring each year over the past several decades, the incidence of the disease has rising worldwide, increasing in developing and developed countries. It comprises $17 \%$ of all cancers ${ }^{(1)}$.

Female breast cancer is the most commonly diagnosed malignancy amongst women worldwide (23\% of all new cancer cases), with an incidence rate $>$ twice that of colorectal cancer and cervical cancer, and about three times that of lung cancer. It is the second leading cause of cancer deaths in women today secondary to lung cancer ${ }^{(2)}$.

In Egypt, breast cancer represents the most common cancer among Egyptian females and constitutes $37 \%$ of all female cancers ${ }^{(3)}$.

The age standardized rate (ASR) for breast cancer incidence in Egypt is 37.3 compared to 76 in the United States. Although incidence remains significantly lower than in highly developed countries, rates are steadily increasing ${ }^{(4)}$.

The diagnostic process of breast cancer is made by a combination of clinical assessment, radiological imaging and a tissue sample taken by either cytological or histological analysis that is called triple assessment ${ }^{(5)}$.

Once a diagnosis is made, a treatment plan is formulated for each individual patient. The multidisciplinary approach for breast cancer is used in planning treatment and all available options are considered in order to optimize cancer control ${ }^{(6)}$.

This may include treatment options as surgery, endocrine therapy, chemotherapy, and radiotherapy. Adjuvant therapies are usually offered after surgery but can sometimes be given beforehand when it is termed neoadjuvant ${ }^{(6)}$.

Surgery remains the mainstay of treatment for breast cancer despite recent and continuing advances in medical treatment ${ }^{(6)}$.

The most frequent early complication of breast cancer surgery is seroma formation, with reported rates of $3 \%$ to $92 \%$. A seroma is a serous fluid collection which may develop in the space between the chest wall and skin flaps following mastectomy or axillary lymph node dissection for breast cancer. Exact pathophysiology of seroma is still debatable. Reasons that may account for the occurrence of seroma include a large operative field, division of lymphatic channels, the loose axillary skin hollow that follows surgical resection and the highly mobile, dependent nature of the area ${ }^{(7)}$.

Seroma is often encountered for no obvious reason and without prodromal warning. Due to its commonality some authors consider seroma a "necessary evil;" which will occur unpredictably in a predictable number of patients ${ }^{(7)}$.

Although seroma is not life threatening and usually painless, it can lead to significant morbidity including flap necrosis, wound dehiscence, predisposes to sepsis, prolonged recovery period, 
lymphedema, multiple physician visits and may delay adjuvant therapy ${ }^{(8)}$.

Various modalities have been used over the decades to reduce seroma formation. Most of them attempt to reduce dead space under the skin flaps and drain any collections which build up under them. These include application of bovine thrombin, fibrin glue and sealant, fixation of flaps to underlying muscle or fascia and use of drains to evacuate any collections and even external compression by pressure garment and dressing ${ }^{(9)}$.

Therefore, ideal wound closure should minimize lymph spillage and serum oozing, provide a means of holding skin flaps securely to the chest wall structures, obliterate dead space, and allow rapid removal of fluid as it forms. It appears that suture flap fixation does reduce seroma formation $^{(10)}$.

Aim of work: Is to evaluate the feasibility and efficacy of fixation of skin flaps to anterior chest wall for closing postoperative space with drainage as an alternative to the classic form of mastectomy closure with closed suction drain for MRM for female patients with breast cancer as regard safety, operative time, hospital stay, postoperative complication, amount of seroma compared between both groups, duration of drain needed to evacuate postoperative seroma.

\section{PATIENTS AND METHODS}

Between 2015 and 2017; a total of 60 female patients with breast cancer in need of modified radical mastectomy were included in this study, our study was assigned on a randomized basis according to a 1:1 ratio and patients underwent post mastectomy closure of the wound either by flap fixation or classical closure. Randomly, we used single blind technique. After giving written consent, they were randomly divided into two groups. Group A $(n=30)$ were managed by flap fixation to anterior chest wall while group B $(n=30)$ were managed by classical closure of skin flaps. Patients' age ranged from 32 to 75 years. All patients were presented with breast cancer in need to do modified radical mastectomy as treatment. Patients were followed up for 30 days and results were recorded and compared. The study was approved by the Ethics Board of Ain Shams University.

The inclusion criteria were: Adult females with biopsy proven breast cancers whom are candidate for MRM
The exclusion criteria were: Simultaneous procedure (Reconstruction, Sentinel lymph node biopsy). Breast cancer cases not suitable for MRM.

Preoperative evaluation: Full history taking, complete physical examination including breast examination, full routine preoperative laboratory tests, preoperative chest $\mathrm{x}$-ray and bilateral mammography and/or ultrasound, computed tomography imaging (CT) of chest if needed. Abdominal ultrasound and or CT of abdomen, pathological diagnosis should be obtained by core needle or fine needle biopsy.

Surgical Technique: All patients in both groups underwent modified radical mastectomy under general anesthesia; all the same classical technique except in closure of the wound. Group A after completing the modified radical mastectomy procedure, using fine absorbable sutures (vicryl 3/0), multiple alternating stitches $3 \mathrm{~cm}$ apart were taken, in rows, between the subcutaneous tissues of the skin flaps and the underlying muscles at various parts of the flaps and also, at the wound edge. Special attention was taken to the obliteration of the largest potential dead space, the empty axillary apex. Closed suction drains were used, while in Group B skin flaps were closed in classic way. Operative time, any intraoperative complications were recorded.

Postoperative Evaluation: All patients were kept in the ward for a day or two for follow up of any wound failure, checking flaps vitality and occurrence of postoperative bleeding then discharged home with drain and outpatient follow up. At each visit patients were asked about drain recoded volumes and examined for any wound failure symptoms.

Data recording and follow up: Data were collected from patient records, medical files and interviews. The documented preoperative, operative and postoperative follow up data for all patients were collected and reviewed. The outcome of both surgeries were evaluated. Results were compared to other studies. All data collected were entered into our spss data sheet and for all result mean and stander divation were calculated and correlation $\mathrm{p}$ value was given in the following results

\section{RESULTS}

Demographic data of the studied cases (total number was 60 patients), mean age was $52.00 \pm 8.465$ year (range 38-75) for group A, while for group B the mean age was $53.00 \pm$ 10.567 (range 32-73). (Table 1). 
Table (1): Shows patients age distribution in each group.

\begin{tabular}{|l|c|c|c|c|c|}
\hline Group & Minimum & Maximum & total & Mean & $\begin{array}{c}\text { Std. } \\
\text { Deviation }\end{array}$ \\
\hline $\begin{array}{l}\text { Group } \\
\text { A }\end{array}$ & 38 & 75 & 30 & 52.00 & 8.465 \\
\hline $\begin{array}{l}\text { Group } \\
\text { B }\end{array}$ & 32 & 73 & 30 & 53.00 & 10.567 \\
\hline
\end{tabular}

Table (2): Shows preoperative comorbidities.

\begin{tabular}{|c|c|c|c|c|}
\hline \multirow{2}{*}{ Comorbidities } & \multicolumn{4}{|c|}{ Groups } \\
\hline & \multicolumn{2}{|c|}{ Group A } & \multicolumn{2}{|c|}{ Group B } \\
\hline \multicolumn{5}{|c|}{ Myocardial infarct } \\
\hline No & 29 & 96.7 & 29 & 96.7 \\
\hline Yes & 1 & 3.3 & 1 & 3.3 \\
\hline \multicolumn{5}{|l|}{ DM } \\
\hline No & 28 & 93.3 & 29 & 96.7 \\
\hline Yes & 2 & 6.7 & 1 & 3.3 \\
\hline \multicolumn{5}{|l|}{ HTN } \\
\hline No & 26 & 86.7 & 27 & 90 \\
\hline Yes & 4 & 13.3 & 3 & 10 \\
\hline \multicolumn{5}{|c|}{ Bleeding tendency } \\
\hline No & 30 & 100 & 29 & 96.7 \\
\hline Yes & 0 & 0 & 1 & 3.3 \\
\hline
\end{tabular}

This table shows preoperative comorbidities as seen above all cases shows nearly similar percentage of comorbidities.

Table (3): Shows diseased breast laterality.

\begin{tabular}{|l|c|c|c|c|c|c|}
\hline \multirow{2}{*}{ Laterality } & \multicolumn{3}{|c|}{ Group } & \multicolumn{2}{|c|}{ Total } \\
\cline { 2 - 5 } & \multicolumn{2}{|c|}{ Group A } & \multicolumn{2}{|c|}{ Group B } & \multicolumn{2}{|c|}{} \\
\hline Left & 15 & 50 & 14 & 46.7 & 29 & 48.3 \\
\hline Right & 15 & 50 & 16 & 53.3 & 31 & 51.7 \\
\hline Total & 30 & 100 & 30 & 100 & 60 & 100 \\
\hline
\end{tabular}

As for breast laterality group $\mathrm{A}$ is divided equally into both sides, also group B is nearly divided into equal groups

Table (4): Shows postoperative histological diagnosis.

\begin{tabular}{|l|c|c|c|c|c|c|}
\hline \multirow{2}{*}{\multicolumn{1}{c|}{ Pathology }} & \multicolumn{4}{c|}{ Group } & \multicolumn{2}{c|}{ Total } \\
\cline { 2 - 6 } & Group A & \multicolumn{2}{c|}{ Group B } & \multicolumn{2}{c|}{} \\
\hline $\begin{array}{l}\text { Invasive ductal } \\
\text { carcinoma }\end{array}$ & 25 & 83.3 & 27 & 90 & 52 & 86.7 \\
\hline Adenocarcinoma & 1 & 3.3 & 2 & 6.7 & 3 & 5 \\
\hline Papillary carcinoma & 4 & 13.3 & 0 & 0 & 4 & 6.7 \\
\hline Lobular carcinoma & 0 & 0 & 1 & 3.3 & 1 & 1.7 \\
\hline Total & 30 & 100 & 30 & 100 & 60 & 100 \\
\hline
\end{tabular}

In both groups invasive duct carcinoma was the major postoperative histological classification by $83.3 \%$ in group A and $90 \%$ in group B while the rest of histological classification occupy nearly about $10 \%$ of all cases
Table (5): Shows tumor stage and lymph node classification.

\begin{tabular}{|l|c|c|c|c|}
\hline \multirow{2}{*}{ Stage } & \multicolumn{4}{c|}{ Groups } \\
\cline { 2 - 5 } T Stage & \multicolumn{2}{|c|}{ Group A } & \multicolumn{2}{c|}{ Group B } \\
\hline T1 & 8 & 26.7 & 6 & 20 \\
T2 & 20 & 66.7 & 22 & 73.3 \\
T3 & 2 & 6.7 & 2 & 6.7 \\
T4 & 0 & 0.0 & 0 & 0.0 \\
\hline N Stage & 4 & 13.3 & 8 & 26.7 \\
Nx & 2 & 6.7 & 6 & 20 \\
N0 & 24 & 80 & 16 & 53.3 \\
N(more)
\end{tabular}

As seen in chart both groups have nearly the same distribution of tumor grading.

\section{Postoperative assessment}

Table (6): Number of days till removal of drain.

\begin{tabular}{|l|c|c|c|}
\hline \multirow{2}{*}{$\begin{array}{l}\text { No. of Days for } \\
\text { drain removal }\end{array}$} & \multicolumn{2}{|c|}{ Group } & \multirow{2}{*}{ Total } \\
\cline { 2 - 3 } & Group A & Group B & \\
\hline 7 & 23 & 18 & 41 \\
\hline 9 & 1 & 1 & 2 \\
\hline 11 & 2 & 1 & 3 \\
\hline 14 & 3 & 7 & 10 \\
\hline 21 & 0 & 3 & 3 \\
\hline 24 & 1 & 0 & 1 \\
\hline Total & 30 & 30 & 60 \\
\hline
\end{tabular}

Table (7): Group A drain duration with total seroma value.

\begin{tabular}{|l|c|c|c|c|c|}
\hline & N & Minimum & Maximum & Mean & $\begin{array}{c}\text { Std. } \\
\text { Deviation }\end{array}$ \\
\hline $\begin{array}{l}\text { Drain No. } \\
\text { of days }\end{array}$ & 30 & 7 & 24 & 8.60 & 3.692 \\
\hline $\begin{array}{l}\text { Total } \\
\text { seroma } \\
\text { volume }\end{array}$ & 30 & 150 & 3170 & 932.00 & 801.591 \\
\hline
\end{tabular}

Table (8): Group B drain duration with total seroma value.

\begin{tabular}{|l|c|c|c|c|c|}
\hline & N & Minimum & Maximum & Mean & $\begin{array}{c}\text { Std. } \\
\text { Deviation }\end{array}$ \\
\hline $\begin{array}{l}\text { Drain } \\
\text { No. of } \\
\text { days }\end{array}$ & 30 & 7 & 21 & 10.23 & 4.688 \\
\hline $\begin{array}{l}\text { Total } \\
\text { seroma } \\
\text { volume }\end{array}$ & 30 & 550 & 4750 & 1500.00 & 908.826 \\
\hline
\end{tabular}


Table (9): Showing total seroma value of both groups.

\begin{tabular}{|c|c|c|c|}
\hline \multirow[t]{2}{*}{ Groups } & \multicolumn{2}{|c|}{$\begin{array}{l}\text { Total amount of } \\
\text { drained fluid }(\mathrm{ml})\end{array}$} & \multirow{2}{*}{$\begin{array}{l}\text { P value } \\
\text { for } t \text { test }\end{array}$} \\
\hline & Range & Mean \pm & \\
\hline $\mathrm{A}$ & $150-3170$ & $932.00 \pm 801.591$ & \multirow{2}{*}{0.013} \\
\hline B & $550-4750$ & $1500.00 \pm 908.826$ & \\
\hline
\end{tabular}

Table (10): Showing drainage duration for both groups.

\begin{tabular}{|l|cc|ccc|c|}
\hline \multirow{2}{*}{ Groups } & \multicolumn{4}{|c|}{ Drainage duration in days } & \multirow{2}{*}{ P value for } \\
\cline { 2 - 5 } & \multicolumn{2}{|c|}{ Range } & Mean & \pm & SD & \\
t test
\end{tabular}

For both groups the minimum number of drainage days was 7 , which is logical as it was 1 st date of follow up in clinic In group A, the maximum drainage days was 24 with mean $8.60 \pm$ 3.692 with minimum seroma volume 150 and maximum 3170 with a mean value of 932.00 \pm 801.591 . On the other hand, Group B maximum number of drainage days was 21 with the mean value $10.23 \pm 4.688$ and minimum seroma volume 550 and maximum 4750 .

As for drainage number of days, the $\mathrm{p}$ was $(0.140)>0.05$ indicating insignificant difference between the 2 groups.

Since $p$ value was $(0.013)<0.05$ in total seroma volume, we can conclude that the mean for group A was significantly lower than group B. which clearly shows that group A has less mean value for total seroma volume.

Table (11): Postoperative complication for both groups.

\begin{tabular}{|l|c|c|}
\hline \multirow{2}{*}{\multicolumn{1}{c|}{$\begin{array}{c}\text { Postoperative } \\
\text { complication }\end{array}$}} & \multicolumn{2}{c|}{ Group } \\
\cline { 2 - 3 } & Group A & Group B \\
\hline Seroma accumulated & 1 & 7 \\
\hline Infected seroma & 0 & 2 \\
\hline Wound gap & 0 & 2 \\
\hline Wound infection & 0 & 1 \\
\hline $\begin{array}{l}\text { Bad cosmetic and } \\
\text { contracture }\end{array}$ & 2 & 0 \\
\hline Hematoma formation & 1 & 0 \\
\hline Pearson Chi-Square & \multicolumn{2}{|c|}{0.049} \\
\hline
\end{tabular}

In this study 4 cases were complicated in group A as 1 patient had seroma accumulated post drain removal, 2 cases had bad cosmetic disfigurement and both of them underwent plastic repair later on and in one case hematoma was formed and it was resolved by conservative treatment. On the other side group B had 7 cases of reaccumulated seroma, 2 cases had infected seroma, 2 cases of wound gap and wound failure and one case of wound infection. All the cases were treated later on according to the condition.

$\mathrm{P}$ value for postoperative complication in comparing the groups was 0.049 showing significant difference in complications of the groups, more in group B than group A.

Chi square test was conducted testing the relation between past history and postoperative complication $(\mathrm{p}=0.004)$ and it showed significant relation between postoperative complication and past history.

\section{DISCUSSION}

Seroma is an accumulation of serous fluid that develops following the formation of skin flaps during mastectomy or in the axillary dead space in the immediate or acute postoperative period ${ }^{(9)}$.

Seroma presents the commonest postoperative complication following mastectomy operations ${ }^{(11)}$. It leads to patient discomfort and prolongation of the hospital stay.

Ideal wound closure should minimize lymph spillage and serum oozing, provide a means of holding skin flaps securely to the chest wall structures, obliterate dead space, and allow rapid removal of fluid as it forms. For this, several techniques of flap fixation or wound drainage, as well as limitation of postoperative shoulder movement and the use of adhesive glue, have been investigated to improve primary healing and minimize seroma formation ${ }^{(9)}$.

In this study 60 females suffering from breast cancer and in need for modified radical mastectomy procedure patients were divided into 2 groups: group A flap fixing group and group B non-flap fixing group. Both groups were followed and seroma volume was calculated as collected from drain and number of days till drain removed was recorded and we found the following:-

In group A about $77 \%$ of the cases removed the drain in the 7 th day with mean value of 8.6 days to remove the drain in comparison with group B in which only $60 \%$ of the cases removed drain by the 7 th day with a mean value of 10.23 days to remove the drain the p value was $(0.140)>$ 0.05 indicating insignificant difference between the 2 groups, yet we still have more patients removing drain in the first clinic visit in group A than in group B. 
These data are similar to data gathered in research done by Sakkary ${ }^{(14)}$, in which a sample 135 patients, 76 underwent flap anchoring without drainage and 59 had routine drainage without flap fixation. The length of hospital stay was reduced in the flap fixation group: 1.88 vs. 2.67 days in nonfixing group $(p<0.0001)^{(14)}$.

However this research showed no difference in total seroma volume between both groups $49 \%$ vs. $59 \%(\mathrm{p}=0.22)$ unlike our research that showed $p(0.013)$ between both group A and B which confirmed reduced mean value of total seroma in flap fixing group than flap fixing. On contrary, the method of research done by Sakkary was slightly different as patient with flap fixing didn't have drain while in our research all patient had drain inserted. Also Sakkary study showed six patients to one wound infection more in flap fixing group. This was also not similar to our study which showed more wound infection rate in non-fixing group $^{(14)}$.

It was also noticed that in our series total amount of seroma in group A showed a mean value of 801.5 in comparison to mean value of 1500 in group B. The difference was highly significant and so it is apparent how total volume of seroma was reduced by flap fixation.

Another study was done by Sakkary ${ }^{(14)}$ between June 2009 and July 2010 where forty patients with breast carcinoma, scheduled for modified radical mastectomy, were randomly divided into 2 groups, the study group (20) and the control group (20). In the study group; the mastectomy flaps were fixed to the underlying muscles in rows, at various parts of the flap and at the wound edge using fine absorbable sutures. In the control group; the wound was closed in the conventional method at the edges. Closed suction drains were used in both groups. Patients, tumor characteristics and operative related factors were recorded. The amount and color of drained fluid were recorded daily. The drains were removed when the amount become less than $50 \mathrm{cc}$. The total amount and duration of drained fluid and the formation of seroma were recorded and the results were compared between the two groups ${ }^{(14)}$.

In that study; the drain in the flap fixation group was removed in significantly shorter time compared to the control group ( $\mathrm{p}<0.001)$. Also, the total amount of fluid drained was significantly lower in the flap fixation group $(p<0.001)$. The flap fixation group showed a significantly lower frequency of seroma formation compared to the control group, both clinically $(\mathrm{p}=0.028)$ and ultrasonographically $(\mathrm{p}=0.047)$ which nearly match results in our study.

It is also noticed that in our series, the overall complications rate was $27 \%(16 / 60)$ with no mortality. This rate is less than that reported in most studies. Reported studies document that surgical morbidity from breast and/or axillary wound occur in up to $30 \%$ of cases ${ }^{(12)}$.

In the current study in group A, only one case got accumulated seroma post removal of drain while in group B 7 cases got accumulated seroma and there were more postoperative complications in group B than group A. Two cases had cosmetic disfigurement in group A but it was believed to be due to over plication of skin flaps to the chest wall and both cases were followed in our patient clinic and later on plastic reconstructive surgery was done for both of them.

In another research done by Renjin (13) from October 2011 to October 2012, patients undergoing modified radical mastectomy for carcinoma of the breast were randomized into two groups of 100 according to wound closure methods: either flap fixation or standard wound closure group. The fluid that collected under the flaps assessed at the physical examination after the drains were removed was defined as seroma for the purpose of the study.

The main parameter which was used to assess the outcome of the study was the number of days the drainage system was required for each patient. Postoperatively, the amount of drain was assessed every day and drain was removed when the amount was less than $50 \mathrm{ml}$ for 2 consecutive days ${ }^{(13)}$. Both our study and that study agreed that average number of days of drain among the experimental group was $12.3+2.4$ and that among the controls was $18.4+2.5(\mathrm{p}<0.001)$.

Median days of drain among the cases and controls, was 12 and 18 and the total amount of drain was more $(875+490 \mathrm{ml})$ in control group as compared to $(670+270 \mathrm{ml})$ that in study group $(\mathrm{p}<0.05)$ which is also similar to our results ${ }^{(13)}$.

Thus both researches agree that flap fixation was an effective method to reduce the incidence of seroma formation and needs favourable attention from surgeons performing 
mastectomies to decrease the incidence of seroma formation $^{(13)}$.

Two cases on group B got infected seroma and two cases got gapped wounds and all complicated cases treated according to complication. Morbidity was significantly reduced with flap fixation.

From the findings of the literature review and based on our experience, it is suggested that the flap fixation technique is a valuable procedure that significantly decrease the total amount of drained fluid, allowing the earlier removal of the drains as well as decreasing the incidence of seroma formation, and the need for frequent visits for seroma fluid aspiration after mastectomy. However, this technique should be tried on a much wider scale to prove its validity in decreasing the incidence of seroma formation and its subsequent complications, so that it can be introduced as a step in the mastectomy operations. However, this technique should be tried on a much wider scale to prove its validity in decreasing the incidence of seroma formation and its subsequent complications, so that it can be introduced as a step in the mastectomy operations.

\section{REFERENCES}

1. Bleyer A, Welch $H$ (2012): Effect of three decades of screening mammography on breastcancer incidence. New England Journal of Medicine, 367(21): 1998-2005.

2. Jemal A, Bray F, Center M, Ferlay J, Ward E, Forman D (2011): Global cancer statistics. CA: a cancer journal for clinicians, 61(2): 69-90.

3. Omar S, Khaled H, Gaafar R, Zekry A, Eissa S, El-Khatib O (2003): Breast cancer in Egypt: A review of disease presentation and detection strategies. East Mediterr. Health J., 9:448-463.

4. Dey S, Soliman A, Hablas A, Seifeldein I, Ismail K, Ramadan M, Harford $\mathrm{J}$ et al. (2010): Urban-rural differences in breast cancer incidence in Egypt (1999-2006). The Breast, 19(5): 417-423.

5. Mack L, Lindsay R, Temple W (2008): Breast Conservation Surgery: Methods. In Methods of Cancer Diagnosis, Therapy and Prognosis (pp. 557 568). Springer, Dordrecht., Website: https:// link. springer. com/ chapter/ 10. 1007/ 978-1-4020-8369-3_38
6. Jacqueline L (2011): The Royal Society of Medicine 'Your Guide to Breast Cancer', clinical outcomes of breast cancer treatment using oncoplatic techniques. Int $\mathrm{J}$ Breast Cancer., 4: 28-37.

7. Agrawal A, Ayantunde A, Cheung K (2006): Concepts of seroma formation and prevention in breast cancer surgery. ANZ Journal of surgery, 76(12): 1088-1095.

8. Loo W, Chow L (2007): Factors predicting seroma formation after mastectomy for Chinese breast cancer patients. Indian Journal of Cancer, 44 (3): 99-103.

9. Pogson C, Adwani A, Ebbs S (2003): Seroma following breast cancer surgery. European Journal of Surgical Oncology (EJSO), 29(9): 711-717.

10. Kuroi K, Shimozuma K, Taguchi T, Imai H, Yamashiro H, Ohsumi S, Saito S (2006): Effect of mechanical closure of dead space on seroma formation after breast surgery. Breast Cancer, 13(3): 260-265.

11. Hashemi E, Kaviani A, Najafi M, Ebrahimi M, Hooshmand H, Montazeri A (2004): Seroma formation after surgery for breast cancer. World journal of surgical oncology, 2(1): 44.

12. Cheng H, Clymer J, Sadeghirad B, Ferko N, Cameron C, Amaral J (2018): Performance of Harmonic devices in surgical oncology: an umbrella review of the evidence. World journal of surgical oncology, 16(1): 2.

13. Renjin R, Sunil S (2017): Effect of Mechanical Closure of Dead Space on Seroma Formation in Modified Radical Mastectomy. Journal of Medical Science and Clinical Research, 5(6): 23126-23132.

14. Sakkary M (2012): The value of mastectomy flap fixation in reducing fluid drainage and seroma formation in breast cancer patients. World Journal of Surgical Oncology, 10(1): 8. 